\title{
PERANCANGAN SISTEM TRANSFER DAYA NIRKABEL UNTUK UNMANNED AERIAL VEHICLE (UAV) MICRO JENIS QUADCOPTER
}

\author{
Setyawan Wahyu Pratomo \\ Jurusan Teknik Elektro, Fakultas Teknologi Industri, Universitas Islam Indonesia \\ "Corresponding author, e-mail : setyawan.wahyu@uii.ac.id
}

\begin{abstract}
Abstrak - Dalam Unmanned Aerial Vehicle ( UAV) jenis Quadcopter, sumber catu daya berupa baterai yang hanya mampu bekerja 10-15 menit di udara merupakan permasalahan tersendiri bagi performa Quadcopter. Sedangkan perfomansi dari Quadcopter pada ketinggian yang susah dijangkau, diharapkan peran operator yang selama ini harus mengkoneksikan secara manual kabel charging ke baterai bisa digantikan oleh sistem secara otomatis ketika baterai akan habis. Untuk itu dalam paper ini membahas suatu perancangan sistem transfer daya nirkabel untuk Quadcopter mengisi ulang baterai tanpa bantuan operator dan tidak harus dilakukan pendaratan di atas tanah. Proses isi ulang (charging) baterai bisa dilakukan di atas gedung maupun di landasan yang telah terpasang transfer daya nirkabel. Tujuannya adalah meningkatkan performansi kerja Quadcopter di udara sesuai dengan kegunaanya. Dari perancangan sistem transfer daya nirkabel untuk Unmanned Aerial Vehicle (UAV) jenis Quadcopter mengisi ulang ( charging ) baterai, diperoleh hasil efisiensi transfer daya terbaik sebesar $62,24 \%$ dengan jarak efektif 10 $\mathrm{cm}$. Frekuensi sistem transfer daya nirkabel diperoleh dari rangkaian Colpitss Oscillator sebesar 333,1 $\mathrm{KHz}$ dengan menerapkan prinsip induksi elektromagnetik.
\end{abstract}

Kata Kunci : Quadcopter, charging baterai, induksi elektromagnetik

\begin{abstract}
In the Unmanned Aerial Vehicle ( UAV) type of Quadcopter, the source of power supply in form of a battery that is only able to work 10-15 minutes in the air is a own issue for the performance of Quadcopter. While the performance of quadcopter at a high that are difficult to reach, it is expected over the role an operator must manually connect the charging cable to battery can be replaced by the system automatically when battery runs out. For that, in this paper discusses design of wireless power transfer system for Quadcopter to charge battery without the help of an operator and not to be done landfalls on the ground. The recharging process of battery can be done at the top of the building or in the common ground that has been installed wireless power transfer. The aim is to improve the performance of quadcopter`s work in the air in accordance with the usefullness. From the design of wireless power transfer system for quadcopter`s charging the battery obtained the results the best efficiency power transfer is 62.24 $\%$ with effective distance $10 \mathrm{~cm}$. The frequency`s system obtained from an Oscillator Colpitss $333,1 \mathrm{KHz}$ by implementing the principles of electromagnetic induction.
\end{abstract}

Keywords : Quadcopter, charging battery,electromagnetic induction

Copyright $@ 2016$ JNTE. All rights reserved

\section{PENDAHULUAN}

Dengan pesatnya perkembangan teknologi semikonduktor dan teknologi nirkabel, perangkat-perangkat elektronik yang dahulu tergolong statis karena bentuknya fisiknya yang besar dan berat sehingga tidak memungkinkan untuk dibawa kemana-mana. Sekarang sudah menjadi perangkat yang ringan dan simple sehingga dapat dibawa kemana-mana [4]. Saat ini, Penelitian yang sedang berkembang pesat dilakukan adalah mengenai sistem transfer daya listrik tanpa kabel (wireless power transfer ) [3]. Pada umumnya transfer daya listrik yang kita gunakan adalah mengunakan media perantara berupa kabel tembaga. Tembaga digunakan sebagai media transfer listrik karena bahannya yang terdiri atas banyak elektron yang bisa bergerak bebas. Sehingga saat dihubungkan dengan suatu sumber listrik maka aliran elektron bisa bergerak dengan bebas pada bahan tersebut. Namun seiring dengan perkembangan teknologi saat ini telah dikembangkan transfer daya listrik nirkabel. Hal ini juga bisa menjadi penghematan terhadap bahan-bahan untuk pembuatan kabel sebagai media penyaluran daya karena digantikan oleh wireless power transfer[8].

Kebutuhan fleksibilitas menjadi parameter utama yang diinginkan dari pengaplikasian sistem transfer daya listrik tanpa kabel 
khususnya bagi Unmanned Aerial Vehicle ( $U A V$ ) jenis quadcopter.

Dengan melihat banyaknya kegunaan quadcopter untuk membantu aktivitas manusia khususnya penginderaan jauh dari udara, ternyata quadcopter masih sangat memiliki keterbatasan dalam hal catu daya listriknya. Permasalahan yang umum terjadi pada quadcopter adalah baterai yang terpasang pada quadcopter hanya mampu bertahan di udara sekitar 15-40 menit tergantung penggunaan. Karena baterai quadcopter hanya memiliki waktu bertahan yang sangat pendek, otomatis baterai tersebut harus di isi ulang kembali atau dilakukan penggantian baterai.

Sehingga ketika baterai mendekati habis, quadcopter harus dilakukan pendaratan untuk proses isi ulang kembali atau penggantian baterai yang mungkin jarak antara lokasi pendaratan dengan objek yang akan diobservasi sangat jauh. Padahal, mobilitas dan fleksibilitas dari penggunaan quadcopter yang begitu banyak menuntut kinerja maksimal dari quadcopter itu sendiri. Permasalahan ini tentunya harus dicarikan alternatif jalan keluar agar utilitas dari quadcopter dapat digunakan seefektif dan seefisien mungkin.

Untuk itu dalam paper ini, peneliti merancang suatu sistem transfer daya nirkabel untuk quadcopter ini agar mampu melakukan proses pengisian ulang baterainya secara nirkabel dan tidak harus ada operator yang standby di suatu lokasi pendaratan hanya untuk melakukan proses isi ulang baterai atau penggantian baterai. Dengan mengaplikasikan konsep teknologi transfer daya nirkabel pada quadcopter, memungkinkan quadcopter untuk melakukan pendaratan di daerah yang susah untuk dijangkau ( edge environment) untuk melakukan proses isi ulang baterai secara otomatis tanpa bantuan operator seperti di atas gedung dan lain sebagainya tanpa harus selalu dilakukan pendaratan di atas tanah dengan bantuan operator untuk memaksimalkan kinerja dari quadcopter itu sendiri.

\section{TINJAUAN PUSTAKA}

\subsection{Teori Induksi Elektromagnetik Bersama}

Ketika terdapat 2 kumparan $\left(L_{1} \& L_{2}\right)$ yang saling berdekatan satu sama lain pada suatu jarak tertentu dimana arus $i_{1}$ diberikan pada sebuah kumparan $L_{1}$ maka akan muncul fluks magnetik $\Phi_{B}$ yang melewati kumparan $L_{2}$ ditunjukkan pada gambar 1 (a) \& (b) berikut [7],

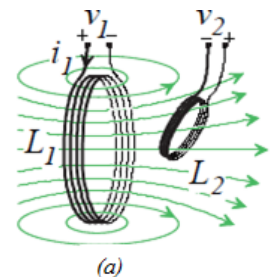

(a)

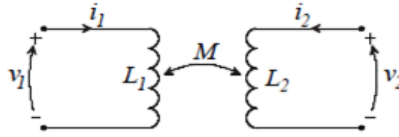

(b)
Gambar 1. (a) 2 buah kumparan $\mathrm{L}_{1} \& \mathrm{~L}_{2}$

( $b$ ) Model Skema rangkaian elektronika

Jika fluks magnetik $\Phi_{B}$ ini terjadi karena perubahan arus $i_{1}$ yang melalui kumparan $L_{1}$, maka akan terjadi induksi gaya geruak listrik pada kumparan $L_{2}$, hal ini sesuai dengan Hukum Faraday. Besarnya gaya gerak listrik yang menginduksi kumparan $L_{2}$ akan terakumulasi sehingga mengakibatkan muncul nya tegangan $v_{2}$ pada terminal kumparan $L_{2}$ yang dapat diketahui melalui persamaan (2.1) berikut,

$$
v_{2}(t)=n_{2} \cdot \frac{d \Phi_{B}(t)}{d t}
$$

Dimana $n_{2}$ merupakan jumlah lilitan pada kumparan $L_{2}$ dan $\Phi_{B}$ merupakan besarnya fluks magnetik. Besarnya fluks magnet $\Phi_{B}$ yang terjadi sebanding dengan besarnya arus $i_{1}$ yang melalui kumparan $L_{1}$ yang dapat diketahui melalui persamaan (2.2) berikut ini,

$v_{2}(t) \approx n_{2} \cdot \frac{d i_{1}(t)}{d t} \Leftrightarrow v_{2}(t)=M_{12} \cdot \frac{d i_{1}(t)}{d t}$

dimana $M_{12}$ merupakan koefisien induktansi bersama. Kemudian, fenomena induksi elektromagnetik yang terjadi pada kumparan $L_{2}$ juga terjadi pada kumparan $L_{1}$ dimana sebuah arus $i_{2}$ yang melalui kumparan $L_{2}$ akan menginduksi kumparan $L_{1}$. Sehingga muncul tegangan $v_{1}$ pada kumparan $L_{1}$ yang dapat diketahui melalui persamaan (2.3) berikut ini, 
$v_{1} \approx n_{1} \cdot \frac{d i_{2}(t)}{d t} \Leftrightarrow v_{1}(t)=M_{21} \cdot \frac{d i_{2}(t)}{d t}$

Dapat diketahui dari persamaan (2.3) di atas bahwa $M_{12}=M_{21}$ merupakan koefisien induktansi bersama. Besarnya nilai tegangan $v_{1}, v_{2}$ ini bergantung pada jumlah lilitan $n_{1}, n_{2}$, bentuk dan fungsi geometri kumparan, koefisien induktansi bersama, serta material disekitarnya yang mempengaruhi besarnya medan magnet.

\subsection{Kopling Magnetik ( $k$ )}

Pada proses induksi elektromagnetik yang terjadi pada transfer daya nirkabel, besarnya jarak antara kumparan pengirim dan penerima merupakan suatu parameter yang harus diketahui. Besarnya jarak yang dapat diperoleh antara kumparan pengirim dan penerima itu tergantung pada besarnya fluks magnet yang terjadi diantara 2 kumparan tersebut. Dalam proses induksi elektromagnetik yang terjadi, hanya sebagian kecil fluks magnet yang dihasilkan oleh kumparan perangkat pengirim dapat diterima oleh kumparan perangkat penerima yang berkontribusi pada proses transfer daya listrik.

Semakin banyak fluks magnet yang dapat ditangkap oleh kumparan perangkat penerima berarti semakin baik kopling magnetik yang terjadi. Tingkatan dari besarnya kopling magnetik yang terjadi ditunjukkan dengan besarnya suatu koefisien kopling magnetik ( $\mathrm{k}$ ).

Besarnya nilai koefisien kopling magnetik ini berkisar dari 0 sampai dengan 1 . Nilai 1 ini menunjukkan bahwa fluks magnetik yang dihasilkan oleh perangkat pengirim dapat ditangkap secara penuh oleh kumparan perangkat penerima. Kemudian apabilan koefisien kopling magnetik ini bernilai mendekati 0 maka kumparan perangkat pengirim dan penerima saling independen satu sama lain atau tidak terjadi induksi di antara 2 kumparan ini.

Besarnya kopling magnetik (k) ditentukan oleh 2 parameter penting yaitu posisi antara kumparan pengirim dan penerima dan besarnya bentuk dan ukuran dari kumparan perangkat pengirim dan penerima. Perpindahan posisi antara kumparan pengirim dan penerima mengakibatkan penurunan kopling magnetik (k) yang terjadi.
Besarnya nilai kopling magnetik ( $\mathrm{k}$ ) dapat diketahui dari persamaan (2.4) berikut,

$$
k=\frac{L_{12}}{\sqrt{L_{11} \cdot L_{22}}}
$$

dimana $\mathrm{L}_{12}$ merupakan induktansi bersama sedangkan $\mathrm{L}_{11}$ dan $\mathrm{L}_{12}$ merupakan induktansi sendiri. Persamaan (2.4) di atas diperoleh dari persamaan umum induktansi bersama berikut ini[2],

$$
\begin{aligned}
& \frac{v_{1}}{j \omega}=L_{11} \cdot i_{1}+L_{12} \cdot i_{2} \\
& \frac{v_{2}}{j \omega}=L_{12} i_{1}+L_{22} \cdot i_{2}
\end{aligned}
$$

dimana $v_{1}, v_{2}$ merupakan tegangan yang terdapat pada kumparan pengirim dan penerima. Sedangkan $i_{1}$ dan $i_{2}$ merupakan arus yang mengalir pada kumparan pengirim dan penerima. Kemudian induktansi bersama ditunjukkan oleh $L_{12}=L_{21}$.

Secara sederhana, kopling magnetik dapat diketahui dari suatu sistem yang merupakan relatif dari loop terbuka tegangan $v$ sebagai berikut,

$$
v=\frac{v_{2}}{v_{1}}=k \sqrt{\frac{L_{22}}{L_{11}}}
$$

Untuk nilai $L_{1}=L_{2}$, maka kopling magnetik ( $\mathrm{k})$ dapat ditentukan dari perbandingan antara tegangan di kumparan penerima $\left(v_{2}\right)$ dan tegangan di kumparan pengirim $\left(v_{1}\right)$ dalam rms.

\subsection{Resonansi Magnetik}

Resonansi elektromagnetik erat hubungan nya dengan fenomena medan elektromagnet yang juga erat hubungannya dengan proses terjadinya aliran listrik. Radiasi dari medan elektromagnet pada tingkat tertentu dapat menjadi berbahaya bagi kelangsungan hidup organisme yang berada didalam jangkauannya.

Medan elektromagnet dapat digolongkan dalam medan listrik dan medan magnet. Dan karena medan magnet jauh lebih aman bila dibandingkan dengan medan listrik, maka 
medan magnet menjadi pilihan yang paling tepat untuk digunakan sebagai media pengiriman energi jika dibandingkan dengan medan listrik dalam pemanfaatannya untuk perpindahan energi secara resonansi elektromag netik.

Secara umum, sistem resonansi elektromagnetik dengan resonansi frekuensi memiliki kesamaan yaitu sama-sama memiliki nilai efektif pada jarak tertentu. Apabila di dalam jarak efektif tersebut terdapat sumber medan elektromagnet atau penangkap gelombang elektromagnet lain yang memiliki frekuensi resonansi yang sama dengan sistem sebelumnya ,maka akan dapat bergabung dengan sistem resonansi elektromagnet yang telah ada dan akan membentuk hubungan resonansi elektromagnet yang lebih besar.

\subsection{Rangkaian Oscillator}

\subsubsection{Oscillator Colpitts}

Oscillator Colpitts adalah salah satu jenis oscillator dengan resonator LC yang digu nakan untuk sistem Wireless Power Transfer.

Rangkaian oscillator Colpitts ini memiliki stabilitas frekuensi yang baik, mudah untuk dilakukan pengaturan frekuensi, dan dapat digunakan pada rentang frekuensi yang cukup besar. Selain itu, rangkaian oscillator Colpitts ini terbilang sederhana sehingga secara nilai ekonomi, memiliki cost yang lebih rendah dalam proses produksi. Pengaturan nilai frekuensi pada oscillator Collpitts dapat dilakukan dengan mengubah nilai kedua kapasitor C1 dan C2 serta L1, sebagaimana ditunjukkan dalam gambar 2 di bawah ini. Sementara untuk nilai C1 dan C2 dapat diperoleh melalui persamaan di bawah ini [5],

$$
C=\frac{C_{1} C_{2}}{C_{1}+C_{2}}
$$

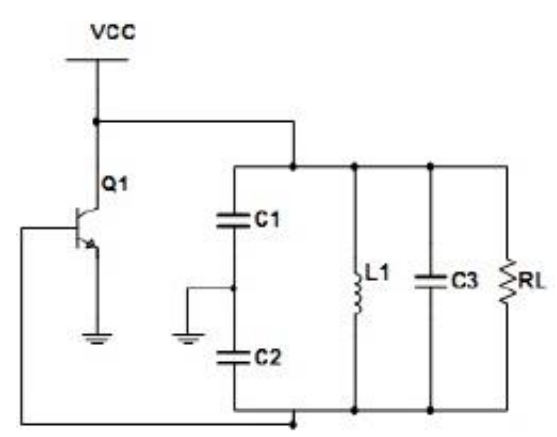

Gambar 2. Rangkaian Collpitts Oscillator

\subsubsection{Oscillator Flyback}

Selain menggunakan oscillator Colpitts, jenis oscillator yang digunakan dalam penelitian Wireless Power Transfer adalah Flyback. Rangkaian oscillator jenis Flyback ini agak berbeda dengan oscillator yang sebelumnya dijelaskan. Rangkaian ini biasanya digunakan sebagai rangkaian driver untuk membuat loncatan elektron dengan menggunakan transformator pada sisi outputnya. Namun pada dasarnya , rangkaian ini memiliki fungsi yang sama dengan rangkaian oscillator sebelumnya, yaitu membangkitkan sinyal AC dari sinyal DC. Bila diperhatikan, rangkaian ini juga memiliki dua komponen utama rangkaian oscillator, yaitu rangkaian penguat dan rangkaian umpan balik[1]. Komponen aktif yang digunakan sebagai penguat adalah MOSFET yaitu Q1 dan Q2, seperti ditunjukkan dalam gambar 3 di bawah ini,

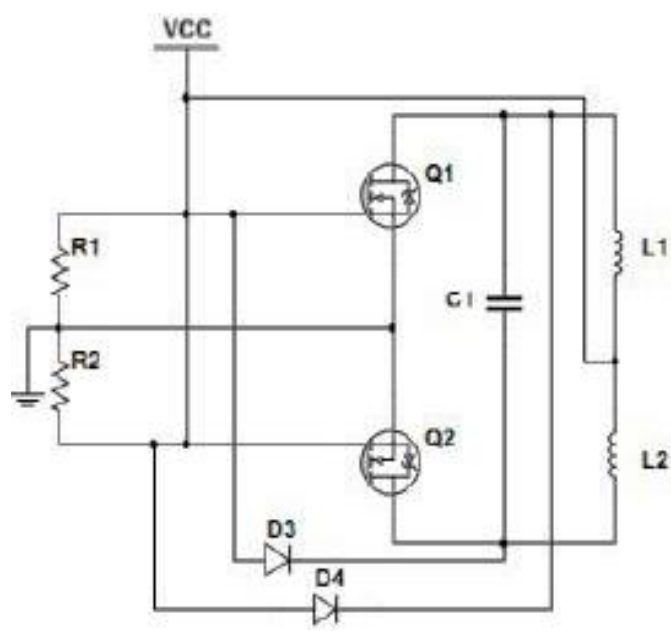

Gambar 3. Rangkaian Flyback Oscillator

Sementara rangkaian umpan balik yang digunakan adalah rangkaian LC yang terdiri dari 2 buah induktor seri, L1 dan L2 serta sebuah kapasitor ,C1. Rangkaian LC Tank ini kemudian di feedback melalui fast recovery diode, D1 dan D2 kepada gate transistor. Besarnya frekuensi osilasi yang dihasilkan dipengaruhi oleh kedua komponen, L1 dan L2. Pada rangkaian oscillator flyback, jenis MOSFET yang digunakan adalah enhancement MOSFET.

\subsection{Quadcopter XK Detect X380}

Quadcopter XK Detect X380 merupakan objek penelitian dalam paper ini dimana quadcopter ini memiliki sumber catu daya dari 
baterai berjenis lithium ion polymer ( Li-Poly ) dengan kapasitas 11,1V ( $3 \mathrm{~S}$ ) 5400mAh. quadcopter ini juga dilengkapi dengan rangkaian balance charger Li-Poly circuit dengan input 12 Volt DC 2 Amp.

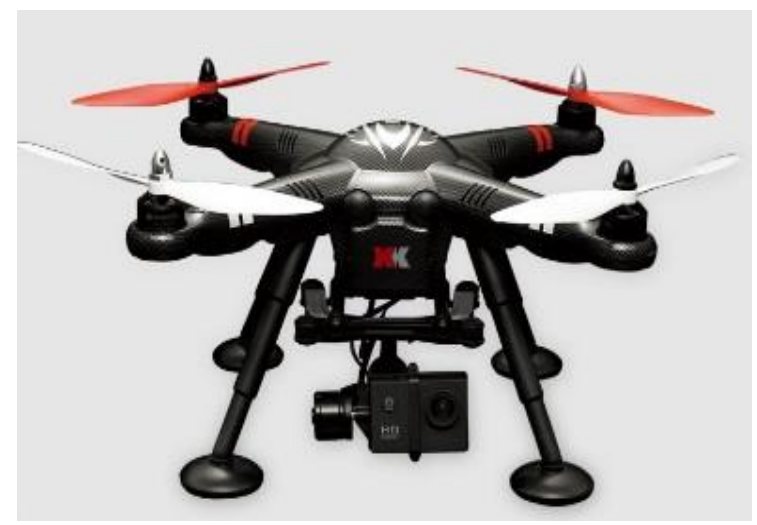

Gambar 4. Quadcopter XK Detect X380

\section{METODOLOGI PENELITIAN}

\subsection{Perancangan Sistem}

Perancangan sistem diilustrasikan pada Gambar 3.1 berikut ini,

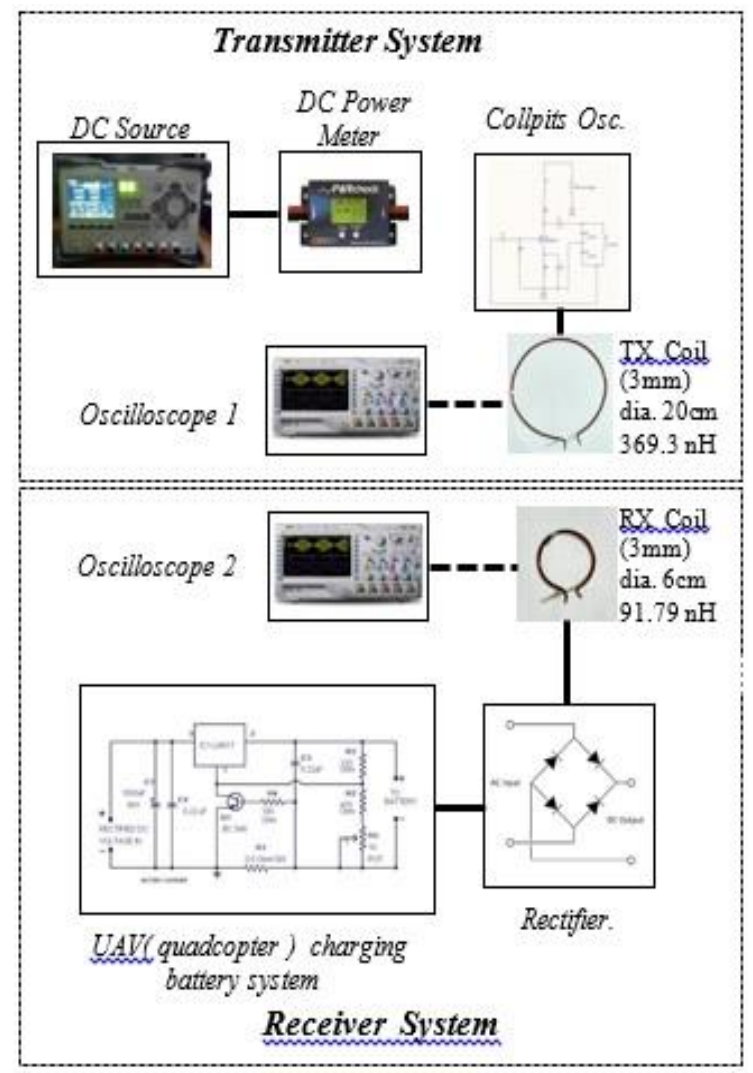

Gambar 5. Rancangan Sistem
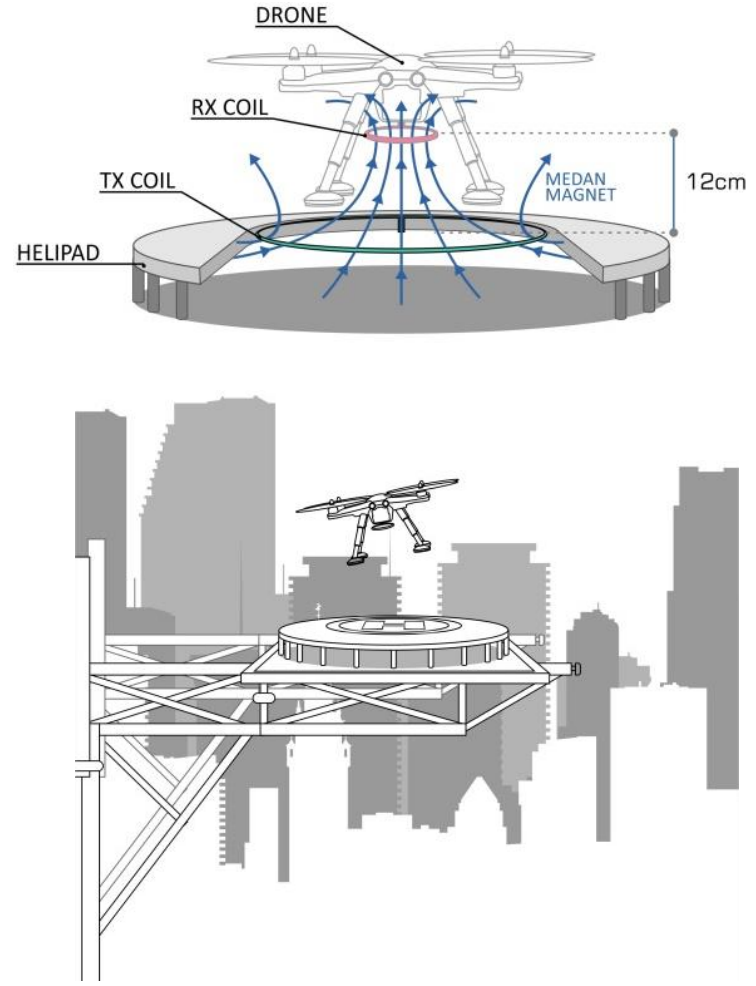

Gambar 6. Ilustrasi sistem

\subsubsection{Perancangan rangkaian transmitter}

Setelah melalui studi literatur telah diketahui konsep dasar rangkaian osilator Colpitts [5] untuk dapat diterapkan dalam sistem transmitter transfer daya nirkabel.

Didalam perancangan Colpitts Oscillator ada beberapa hal penting yang perlu diperhatikan, yaitu :

1. Menentukan nilai frekuensi kerja osilator yang sesuai dengan kumparan silinder pejal yang diinginkan sebesar $369,3 \mathrm{nH}$

2. Mengkondisikan MOSFET agar berada di daerah aktif ketika terjadi induksi elektromagnetik, sehingga kinerja MOSFET mampu maksimal ketika terjadi transfer daya maksimum.

Pada penelitian ini, perancangan Colpitts Oscilator ini ditentukan sepesifikasi sebagai berikut,

1. Tegangan input osilator sebesar 18.5 Volt DC

2. Frekuensi kerja osilator yang diinginkan adalah sebesar $333.1 \mathrm{KHz}$

3. Beban yang digunakan adalah $U A V$ ( quadcopter) charging battery system 12 Volt 2 Amp. 
4. Transmitter coil ( TX ) coil yang digunakan adalah tembaga silinder pejal yang mempunyai inner diameter $3 \mathrm{~mm}$ dengan besar diameter TX coil sebesar $20 \mathrm{~cm}$ dengan nilai induktansi $\quad 369.3 \mathrm{nH}$

5. Receiver coil ( $R X)$ coil yang digunakan adalah tembaga silinder pejal yang mempunyai inner diameter $3 \mathrm{~mm}$ dengan besar diameter RX Coil sebesar $6 \mathrm{~cm}$ dengan nilai induktansi $\quad 91.79 \mathrm{nH}$

Untuk mendapatkan frekuensi kerja sebesar $333.1 \mathrm{KHz}$ pada Osilator Colpitts, maka dilakukan perhitungan untuk menentukan besarnya nilai komponen pada Colpitts, LCResonator dengan persamaan ( 3.1 ) di bawah ini[6],

$$
\begin{aligned}
& f_{\text {Osc }}=\frac{1}{2 \pi \sqrt{L C_{T}}} \\
& (2 \pi f)^{2}=\left(\frac{1}{\sqrt{L C_{T}}}\right)^{2} \\
& 4 \pi^{2} f^{2}=\frac{1}{L C_{T}} \\
& C_{T}=\frac{1}{4 \pi^{2} f^{2} L} \\
& C_{T}=\frac{1}{4 \cdot(3,14)^{2} \cdot\left(333,1 \cdot 10^{3}\right)^{2} \cdot 369,3 \cdot 10^{-9}} \\
& C_{T}=0,618 u F .
\end{aligned}
$$

Dari hasil perhitungan nilai Ctotal $\left(C_{T}\right)$ bernilai $22 \mathrm{nF}$, namun perlu dilakukan perhitungan kembali untuk mendapatkan nilai komponen kapasitor pembagi tegangan pada Colpitts LC- Resonator dengan persamaan (3.2) dibawah ini[5],

$$
\begin{aligned}
& C_{T}=\frac{C_{4} \cdot C_{5}}{C_{4}+C_{5}} \\
& 0,618 u F=\frac{1,236 u F .1,236 u F}{1,236 u F+1,236 u F}
\end{aligned}
$$

didapatkan nilai $\mathrm{C}_{4}=\mathrm{C}_{5}=1,236 \mathrm{uF}$. Sehingga desain rangkaian Osilator Colpitts secara lengkap dapat ditunjukkan dengan gambar 7 di bawah ini,

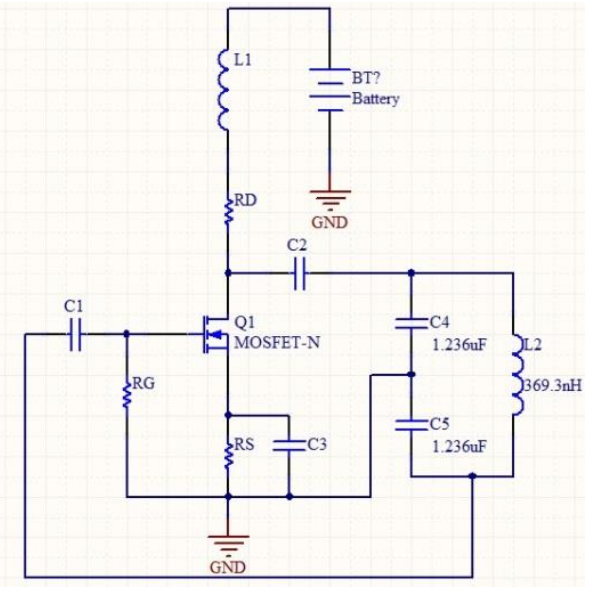

Gambar 7. Colpitts Oscillator ( Transmitter)

\subsubsection{Perancangan rangkaian receiver}

Perancangan rangkaian receiver ( penerima ) ini berfungsi sebagai penerima induksi gelombang elektromagnetik. Rangkaian receiver ( penerima) terdiri dari rangkaian LC yang bertugas menangkap induksi elektromagne tik yang dikeluarkan transmitter dengan semaksimal mungkin dan merubahnya menjadi arus DC.

Untuk mendapatkan penerimaan induksi elektromagnetik yang maksimal dari transmitter maka frekuensi kerja dibuat sama dengan transmitter yaitu sebesar $333,1 \mathrm{KHz}$. Hal ini dimaksudkan untuk mendapatkan frekuensi resonansi dan induktansi bersama antar transmitter dan receiver.

Untuk mendapatkan frekuensi kerja $L C$ Resonator sebesar $333,1 \mathrm{KHz}$ maka dilakukan perhitungan untuk menentukan besarnya nilai komponen pada LC-Resonator pada rangkaian receiver dengan persamaan (3.3) di bawah ini

$$
f=\frac{1}{2 \pi \sqrt{L_{3} C_{6}}}
$$

$(2 \pi f)^{2}=\left(\frac{1}{\sqrt{L_{2} C_{2}}}\right)^{2}$

$4 \pi^{2} f^{2}=\frac{1}{L_{2} C_{2}}$

$C_{2}=\frac{1}{4 \pi^{2} f^{2} L_{2}}$

$C_{2}=\frac{1}{4 \cdot(3,14)^{2} \cdot\left(333,1 \cdot 10^{3}\right)^{2} \cdot 91,79 \cdot 10^{-9}}$

$C_{2}=0.829 u F$ 
Setelah didapatkan nilai komponen $L C$ Resonator, langkah selanjutnya adalah merancang rangkaian dioda penyearah jembatan penuh ( full wave rectifier diode) dengan menggunakan 4 buah dioda jenis Schottky dengan $V_{\text {forward }}$ Diode $=490 \mathrm{mV}$. Kemudian untuk nilai $C_{\text {Stabilizaton }}$ diberikan nilai sebesar $47 \mathrm{nF}$.

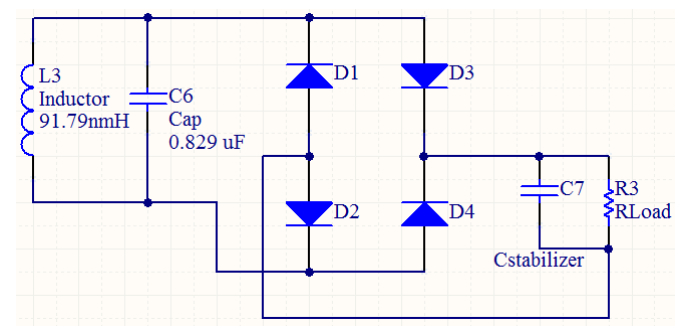

Gambar 8. Receiver Circuit

\section{HASIL DAN PEMBAHASAN}

\subsection{Hasil Pengukuran Daya Input Dan} Output Sistem Transfer Daya Nirkabel

Parameter penting yang diukur dari suatu sistem transfer daya nirkabel adalah daya input dan output. Parameter daya ini merupakan parameter yang menjadi target acuan didalam pembuatan sistem transfer daya nirkabel. Semakin besar daya yang dapat ditransfer berarti sistem transfer daya nirkabel memiliki efiesiensi yang baik.

Tabel 1. Hasil pengukuran daya input dan output sistem dengan beban

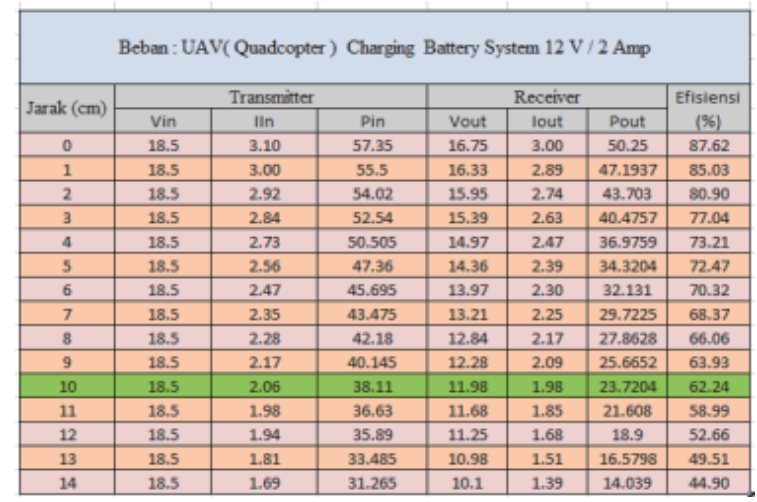

Pengukuran daya input dan output ini menggunakan alat ukur berupa DC powermeter yang memiliki fasilitas datalogging yang secara real time mampu merekam perubahan daya dari sistem transfer daya nirkabel. Hasil pengukuran daya input dan output dari sistem transfer daya nirkabel ditunjukkan pada Tabel 1.

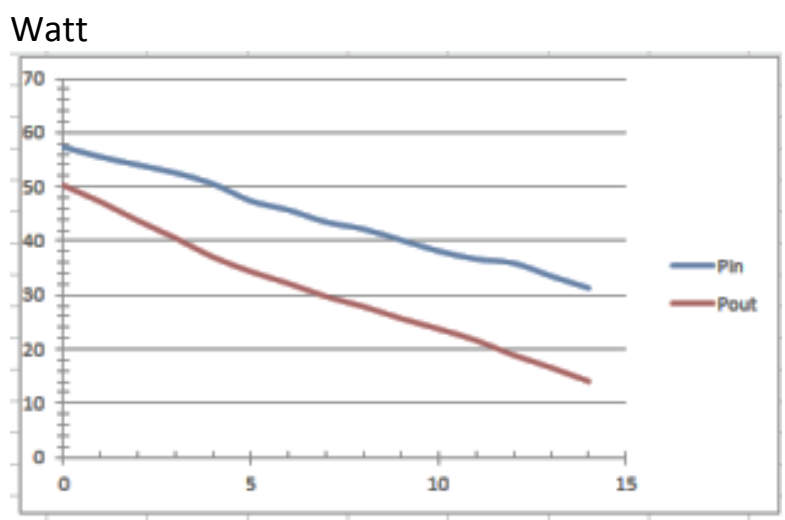

$\operatorname{Jarak}(\mathrm{cm})$

Gambar 9. Grafik daya input ( Pin) dan daya output ( Pout ) sistem transfer daya nirkabel

Hasil pengukuran mengenai daya input Pin ) dan Output ( Pout ) sistem dapat dilakukan analisa sebagai berikut,

Sistem transfer daya nirkabel yang dirancang memiliki kemampuan untuk dapat mensuplai beban UAV (quadcopter) charging battery system dengan daya yakni sekitar 23.704 Watt ( efektif ) pada jarak $10 \mathrm{~cm}$.

Pada saat transmitter didekatkan pada jarak yang sangat dekat yaitu $0 \mathrm{~cm}$ artinya antara kumparan transmitter dan receiver tidak ada penghalang, induksi elektromagnetik berlangsung maksimum, sehingga arus dari transmitter secara maksimum terserap ke receiver. Daya yang dipancarkan oleh transmitter pada jarak $0 \mathrm{~cm}$ sebesar 57.35 Watt hanya diterima 50.25 Watt di receiver. Hal ini dikarenakan kemampuan kopling magnetik dalam proses induksi elektromagnetik yang dihasilkan hanya mampu memberikan efisiensi sekitar $87.62 \%$ pada jarak $0 \mathrm{~cm}$.

Ketika jarak diperlebar secara perlahan, maka akan terjadi penurunan daya yang diterima oleh receiver. Penurunan daya di receiver ini disebabkan oleh semakin kecil induksi elektromagnetik antara transmitter dan receiver, sehingga tegangan yang ditransfer pun menjadi semakin kecil. Semakin kecil tegangan yang ditransfer maka semakin kecil pula tegangan yang terjadi di receiver didalam mensuplai beban. 
Ketika sudah tidak terjadi induksi elektromagnetik antara transmitter dan receiver maka daya yang terbaca di transmitter akan menjadi standby power yaitu sebesar 2,55 Watt.

\subsection{Hasil Pengukuran Kopling Magnetik ( K ) dengan Jarak Transfer Daya}

Parameter penting setelah daya yang diukur dari sistem transfer daya nirkabel adalah kopling magnetik dan jarak maksimum transfer daya. Kopling magnetik menjadi parameter yang menunjukkan efektifitas transfer daya yang berbanding dengan jarak transfer yang mampu ditempuh.

Tabel 2. Hasil pengukuran kopling magnetic dan jarak transfer daya
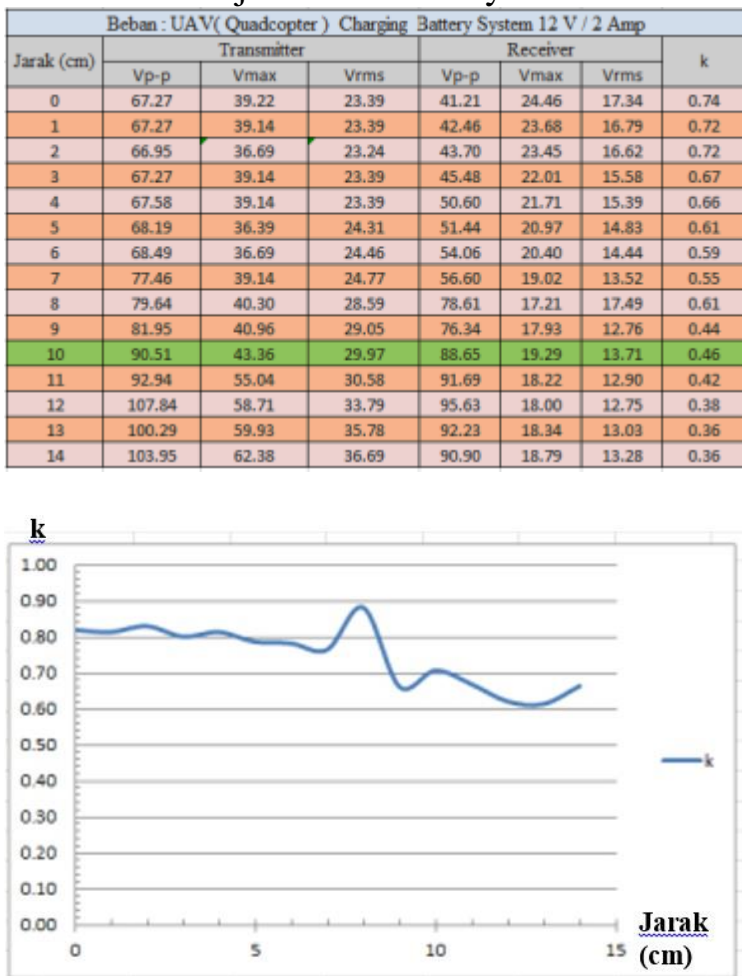

Gambar 10. Grafik karakteristik kopling magnetik

Hasil pengukuran mengenai kopling magnetik sistem dapat dilakukan analisa sebagai berikut,

Ketika transmitter didekatkan dengan receiver pada jarak $0 \mathrm{~cm}$, nilai kopling magnetic yang didapatkan adalah 0.74 . Hal ini berarti pada saat tidak ada penghalang sama sekali antara transmitter dan receiver, fluks magnet yang ditimbulkan oleh arus dan tegangan pada transmitter hanya diserap oleh receiver sebesar $74 \%$. Besarnya fluks magnet yang ditandai dengan nilai kopling magnetik ini akan menurun apabila jarak transmitter dan receiver dijauhkan. Terlihat ketika pada jarak $10 \mathrm{~cm}$ yang merupakan jarak kerja efektif sistem transfer daya nirkabel yang dibuat, kopling magnetic memiliki nilai sebesar 0.46 atau sebesar $46 \%$ fluks magnet yang dipancarkan oleh transmitter diterima oleh receiver.

\section{KESIMPULAN}

Berdasarkan hasil pengukuran dan analisa terhadap sistem transfer daya nirkabel yang telah dirancang dapat ditarik kesimpulan bahwa

1. Sistem transfer daya nirkabel telah dapat melakukan transfer daya untuk UAV ( quadcopter) battery charging system dengan baik.

2. Efisiensi sistem sebesar $62.24 \%$ dapat diperoleh pada jarak $10 \mathrm{~cm}$

3. Nilai kopling magnetik sistem transfer daya nirkabel bekerja efektif pada rentang 0.44 . 0.46

\section{DAFTAR PUSTAKA}

[1] Boylestad,Robert,Nashelsky Louis, Elec tronic Devices and Circuit Theory, Prentice Hall, 1998.

[2] Eberhard Waffenschmidt, Qi Coupling Factor. ,Phillips research, 2013.

[3] Ghaniyya , Zesyara. M.A. " Rancang bangun osilator flyback pada rangkaian pemancar sistem transfer daya nirkabel". Skripsi Jurusan Teknik Elektro.UI. Depok. 2013.

[4] Helmi,Kautsar. " Analisa dan peran cangan transmitter pada penghantar listrik tanpa kabel". Skripsi Jurusan Teknik Elektro.UI. Depok. 2010.

[5] McGowan,Kevin, Semiconductors: from Book to Breadboard, Delmar,Cengage Learning,2012.

[6] Rashid, Muhammad H.,Power electronics handbook, Academic Press, 2007.

[7] Schuylenbergh Van, Koenraad, \& Puers, Robert. , Inductive Powering, Springer, 1993.

[8] Sherly Puspita Rahman, Mas Sarwoko, Zulfi, "PERANCANGAN DAN REAL ISASI PROTOTYPE SISTEM TRANS 
FER DAYA LISTRIK NIRKABEL UN TUK MENGISI BATERAI HAND PHONE" Jnte Fakultas Teknik Unand Vol:2 No.2 September 2013. September 2013.

\section{Biodata Penulis}

Setyawan Wahyu Pratomo, lahir di Surakarta, 26 September 1989. Menerima gelar Sarjana Teknik ( S.T. ) bidang teknik elektro di Institut Teknologi Telkom/Universitas Telkom dan Magister Teknik ( M.T. ) bidang teknik elektro di Universitas Indonesia ( UI). Sekarang penulis berprofesi sebagai dosen di Universitas Islam Indonesia (UII), Yogyakarta di bidang ketenaga listrikan khususnya wireless power transfer. 